\title{
Fragilidades no processo de trabalho na Atenção à Saúde à Mulher em situação de violência sexual
}

\author{
Weaknesses in the work process in Health Care for Women \\ in situations of sexual violence
}

July Grassiely de Oliveira Branco (https://orcid.org/0000-0002-5426-391X) ${ }^{1}$

Luiza Jane Eyre de Souza Vieira (https://orcid.org/0000-0002-5220-027X) ${ }^{1}$

Aline Veras Morais Brilhante (https://orcid.org/0000-0002-3925-4898) ${ }^{1}$

Maxmiria Holanda Batista (https://orcid.org/0000-0002-9069-678X) ${ }^{2}$
${ }^{1}$ Programa de PósGraduação em Saúde

Coletiva, Universidade de Fortaleza. Av. Washington Soares 1321, Edson Queiroz. 60811-905 Fortaleza CE Brasil. julybranco.upa@gmail.com ${ }^{2}$ Programa de PósGraduação em Saúde Pública, Universidade Federal do Ceará. Fortaleza CE Brasil.

\begin{abstract}
This paper aimed to identify in the discourses of managers and workers assisting women in situations of sexual violence the conditions that compromise the care to these women, and the structuring of the network. This is a qualitative study conducted with 19 professionals of these services through semi-structured interviews. The method of discourse analysis underpinned the analytical process, evidencing two discursive formations: weaknesses that affect the work process, and limitations imposed by professional practice. The results indicate that the daily routine of these services is permeated by the lower number and turnover of professionals, poor working conditions, inadequate physical structure for the development of care, as well as gaps in training and awareness. Workers and managers must be urgently assigned to the care teams to reduce turnover, and the implementation of qualified care by these workers, effective incorporation into the service network, ensuring interdisciplinarity, intersectoriality, and comprehensive care, to ensure and respect the sexual and reproductive rights of these women. Key words Sex Offenses, Work, Health Staff
\end{abstract}

Resumo Objetivou-se identificar nos discursos de gestores e trabalhadores que assistem mulheres em situação de violência sexual, as condições que comprometem a atenção à estas pessoas e à estruturação da rede. Pesquisa qualitativa, realizada com 19 profissionais destes serviços por meio de entrevista semiestruturada. O método da análise do discurso balizou o processo analítico evidenciando duas formações discursivas: fragilidades que repercutem no processo de trabalho $e$ limitações impostas pela prática profissional. Os resultados apontam que o cotidiano desses serviços é permeado pela redução do número e rotatividade de profissionais, precárias condições de trabalho, inadequação da estrutura física para o desenvolvimento da atenção, além das lacunas na capacitação e sensibilização. Urge que trabalhadores e gestores sejam efetivados nas equipes de atenção com vistas à redução da rotatividade e à viabilização de uma atenção qualificada por parte destes trabalhadores, incorporação efetiva na rede de serviços, assegurando interdisciplinaridade, intersetorialidade e integralidade da atenção, na garantia e respeito aos direitos sexuais e reprodutivos dessas mulheres.

Palavras-chave Delitos Sexuais, Trabalho, Pessoal de Saúde 


\section{Introdução}

A violência sexual contra a mulher configura-se como uma grave violação dos direitos humanos ${ }^{1}$, relacionada às questões de gênero ${ }^{2}$. A sua magnitude exige ações efetivas para o enfrentamento ${ }^{3}, \mathrm{o}$ que inclui a organização de uma rede de atenção que articule diferentes atores e dispositivos nas áreas da saúde, segurança pública, promovendo ações para prevenção e enfrentamento de forma intra e intersetoriais ${ }^{4}$.

No setor saúde, as ações devem seguir a lógica da integralidade do cuidado, com atenção para as vulnerabilidades sociais, econômicas, ambientais e afetivas ${ }^{5}$, além do reconhecimento das necessidades individuais ${ }^{6}$. Para tal, é demandado aos profissionais de saúde criatividade nas formas de assistência, investimento e desejo para cuidar dos usuários em sofrimento psíquico ${ }^{7}$.

Esses profissionais, contudo, estão expostos a um processo de trabalho com modelos verticalizados, hierarquizados e fragmentados ${ }^{8,9}$. Ao mesmo tempo, precisam seguir regras de gestão que os convocam a se submeter às incertas condições de trabalho ${ }^{7}$. Apesar dos esforços empregados no sentido de modificar os modelos de atenção, a integralidade da assistência é comprometida pela fragmentação dos sistemas de saúde ${ }^{8}$ na oferta de um cuidado pautado nos padrões biomédicos aliada a precarização do trabalho em saúde 7 .

Diante das evidências de fragilidade nas ações de assistência à mulher em situação de violência sexual e da necessidade de reestruturação dos serviços de saúde ${ }^{10}$, emerge a demanda pela avaliação dos processos de trabalho envolvidos. $\mathrm{O}$ conhecimento produzido por essa análise poderá fomentar ações estratégicas de melhoria e qualificação do cuidado, evitando, inclusive, revitimizações às mulheres que buscam pelos serviços.

Nesse contexto, emergiu a indagação: quais as principais fragilidades que interferem no processo de trabalho para a atenção integral à mulheres em situação de violência sexual? Para a compreensão desse fenômeno, objetivou-se identificar nos discursos de gestores e trabalhadores que assistem mulheres em situação de violência sexual, as condições que comprometem a atenção à estas pessoas e à estruturação da rede.

\section{Metodologia}

O município no qual estão inseridas as instituições desta pesquisa situa-se no nordeste brasileiro. Este ocupa o quinto lugar do país em população, com $53,19 \%$ da população do sexo feminino ${ }^{11}$, e com 504 casos de estupro registrados em 2017 o que corresponde a uma taxa de $19,2 / 100.000$ habitantes ${ }^{12}$.

Integraram a pesquisa dezenove trabalhadores: quatro do centro de referência à mulher, $\mathrm{e}$ quinze profissionais de saúde, dentre estes, sete também exerciam a função de gestores que atuam no atendimento à mulher em situação de violência sexual de oito diferentes instituições, dois centros de referência e seis hospitais, atendendo aos critérios de inclusão: atuar no cuidado às mulheres em situação de violência sexual, se disponibilizar a participar da pesquisa, assinar o Termo de Consentimento Livre e Esclarecido (TCLE) e ter, no mínimo, seis meses de experiência no serviço. Excluíram-se trabalhadores afastados das atividades laborais devido a férias, ou licença saúde. A seleção dos trabalhadores participantes se deu com a técnica de bola de neve ${ }^{13}$, mediante a informante chave da área de saúde da mulher, que disponibilizou o contato de um gestor/trabalhador que disparou a entrevista inicial. Com esse acesso solicitou-se que o participante indicasse outro trabalhador da assistência à mulher em situação de violência sexual e, assim, sucessivamente. A saturação dessa etapa se deu quando indicaram pessoa que já havia sido entrevistada.

Foram realizadas entrevistas semiestruturadas, norteadas por questões abertas, possibilitando aos participantes discorrerem livremente sobre protocolo e fluxo de atendimento, encaminhamentos realizados, atividades desempenhadas no atendimento e potencialidades e fragilidades do serviço. Essas foram agendadas previamente, realizadas em local reservado escolhido por cada participante, com duração média de 15 minutos cada. Os áudios foram gravados e transcritos na íntegra. Utilizou-se um protocolo, que consiste em um bloco de notas para registrar observações no dia a dia, reflexões e inquietações oriundas da observação ${ }^{14}$.

Após a transcrição, a análise balizou-se nos princípios da Análise de Discurso $(\mathrm{AD})^{15}$. Deu-se a leitura do material exaustivamente e em profundidade em busca das marcas do discurso que permitissem situar sua materialidade em uma filiação discursiva e, portanto, ideológica ${ }^{16}$. Partindo dessas marcas, os textos foram segmentados e os grupos semânticos organizados, reunindo-se, em seguida, segmentos convergentes. As formações discursivas foram então contextualizadas e associadas aos discursos sociais vigentes, a fim de se fazer emergir as Formações Ideológicas 
que as configuram. Entende-se por formações ideológicas "um conjunto complexo de atitudes e representações que não são 'nem individuais' e 'nem universais', mas se relacionam mais ou menos diretamente a posições de classes em conflitos umas com as outras" 17 , para atingir os processos discursivos. As formações discursivas foram relacionadas as formações ideológicas e aos fenômenos semânticos à luz do contexto socio-histórico, fazendo emergir as memórias discursivas que norteiam os limites do interdiscurso, bem como aquilo que constitui o não-dito ${ }^{16}$. Nesse processo surgiram duas formações discursivas: (i) Potencialidade e Fragilidades que repercutem no processo de trabalho; e, (ii) Limitações impostas pela prática profissional.

Foram respeitados os princípios éticos contidos na Resolução no 466/12 do Conselho Nacional de Saúde ${ }^{18}$. Para salvaguardar as identidades dos trabalhadores, gestores foram utilizadas as letras $\mathrm{T}$ ou $\mathrm{G}$, respectivamente, seguido do numeral $(1, \ldots, 19)$, da seguinte forma $\mathrm{T} 1, \mathrm{~T} 2, \mathrm{G} 1$, G2 e assim sucessivamente. Ao lado da identificação, na primeira referência de cada participante consta formação profissional e o gênero.

\section{Resultados}

\section{Caracterização dos participantes}

Fizeram parte desta pesquisa dezenove trabalhadores (sete também desempenham cargo de gestão) de oito diferentes serviços que assistem mulheres em situação de violência sexual, sendo dois centros de referência e seis hospitais (Tabela $1)$.

\section{Potencialidades e fragilidades identificadas que repercutem no processo de trabalho}

Dentre os pontos levantados pelos participantes emergem potencialidades e fragilidades que repercutem no processo de trabalho. Dentre as potencialidades, destaca-se o atendimento realizado pelos profissionais:

Eu acho que os profissionais procuram atender da melhor maneira, da maneira que eles conseguem né, dando um acolhimento humanizado, dando todo aquele atendimento que ela precisa naquele momento. (T6, enfermagem, feminino).

Entre as fragilidades, destaca-se a redução no quantitativo de trabalhadores como fator que compromete o atendimento integral com acompanhamento programado, não permitindo a sis-
Tabela 1. Distribuição dos participantes de acordo com sexo, faixa etária, situação conjugal, formação profissional, tempo de formação, tempo de atuação no serviço e cursos na área da violência sexual.

\begin{tabular}{|c|c|}
\hline Perfil & Número \\
\hline Participantes & $\begin{array}{l}19 \text { trabalhadores ( } 07 \\
\text { também são gestores) }\end{array}$ \\
\hline \multicolumn{2}{|l|}{ Sexo } \\
\hline Mulher & 18 \\
\hline Homem & 01 \\
\hline \multicolumn{2}{|l|}{ Faixa etária } \\
\hline Até 40 anos & 10 \\
\hline 41 a 50 anos & 03 \\
\hline+50 anos & 06 \\
\hline \multicolumn{2}{|c|}{ Formação profissional } \\
\hline Medicina & 06 \\
\hline Enfermagem & 05 \\
\hline Serviço Social & 05 \\
\hline Psicologia & 03 \\
\hline \multicolumn{2}{|l|}{ Tempo de formação } \\
\hline Até 5 anos & 06 \\
\hline 6 a 10 anos & 02 \\
\hline 11 a 20 anos & 06 \\
\hline+20 anos & 05 \\
\hline \multicolumn{2}{|c|}{ Tempo de atuação no serviço } \\
\hline Até 5 anos & 11 \\
\hline 6 a 10 anos & 01 \\
\hline 11 a 20 anos & 07 \\
\hline \multicolumn{2}{|c|}{$\begin{array}{l}\text { Curso na área de violência } \\
\text { sexual }\end{array}$} \\
\hline Com & 10 \\
\hline Sem & 09 \\
\hline
\end{tabular}

tematização do cuidado a partir das necessidades da usuária:

Então eu não consigo fazer algo sistemático, a cada 15 dias chamar a mulher para vir, dentro do funcionamento hoje, eu não consigo ter uma agenda de marcação de retorno como se fosse um acompanhamento clinico que a gente gerencia melhor. (T2, psicologia, feminino).

Além de não permitir o planejamento das ações, a escassez de trabalhadores reverbera na assistência. Caso o profissional esteja no serviço, $\mathrm{o}$ atendimento é agilizado, como ilustra T1:

Se a gente identifica que ela está bem impactada, tá bem fragilizada emocionalmente e se a psicóloga estiver no serviço, a gente tenta fazer com que a psicóloga já atenda. (T1, serviço social, feminino). 
Contudo, caso o profissional não esteja no serviço, haverá atraso no atendimento específico, quebrando a cadeia de cuidado. Nesse contexto, a organização das escalas dos profissionais constitui-se fator interveniente para o não alcance da integralidade da atenção. T1 reforça o desafio dessa oferta, na medida em que interconecta o baixo quantitativo de profissionais e os desencontros destes com as usuárias do serviço, justificando que:

Como somos só três profissionais, então em muitos momentos ela não vai estar e não necessariamente a usuária vai comparecer no período que ela está, acaba que a assistente social ou a advogada tem que atender. (T1, serviço social, feminino).

Associada a diminuição de recursos humanos, têm-se a perda de insumos necessários para o serviço, a exemplo, da perda do automóvel utilizado para a realização da visita domiciliar que:

Nós realizávamos (...) a essas mulheres, mas a partir do desmonte que vem acontecendo nos últimos anos com as políticas (...) públicas, nós não temos mais um carro para realizar essas visitas. Isso, por conta também da diminuição da equipe em 50\%. (G1, serviço social, feminino).

Ressalta-se, que o município em pauta vivencia a desestruturação da rede de atenção psicossocial, expondo essas mulheres ao sofrimento difuso e ao estreitamento de possibilidades de ser acolhida na restauração e manutenção de sua saúde mental, porque:

(...) fora o encaminhamento para o acompanhamento psicológico, psicoterapêutico que infelizmente na rede municipal nós não temos, o que nós temos são os CAPS que estão funcionando de forma muito precária e que atende transtornos médios e graves, mas é um serviço que não está preparado para atender traumas por exemplo. (G1, serviço social, feminino).

Boa parte dos participantes sinalizou a desarticulação da rede de atenção à saúde mental e fragmentação na busca da integralidade:

Agente entra em contato (CAPS), mas não tem vaga, não tem vaga, aí assim fica na lista de espera. (T12, serviço social, feminino).

Mesmo com as dificuldades citadas, o encaminhamento é realizado para a rede, mas os trabalhadores reconhecem as fragilidades que existem nessa ação o fluxo de saúde mental do estado está totalmente desorganizado e "destruído tá, isso é fato" (G5, medicina, feminino).

No intuito de suprir essa lacuna, trabalhadores utilizam os consultórios de psicologia das universidades para que as usuárias acessem o serviço psicossocial, reconhecendo a incipiência na implementação, implantação e monitoramento das políticas públicas:

Não é fácil, porque o que acontece não se tem estabelecido enquanto política pública atendimento psicoterapêutico, a gente aciona as faculdades, as clínicas escolas. (G1, serviço social, feminino).

Soma-se às fragilidades, a escassez de ações voltadas para capacitação profissional direcionada a atenção à violência sexual, sendo esta identificada por um dos participantes como ponto nevrálgico dos serviços:

Infelizmente nós não somos preparadas para isso, nós não temos curso, nós não temos assim uma extensão que prepara enfermeiros do acolhimento para isso aqui nessa unidade. (T4, enfermagem, feminino).

As lacunas na formação acadêmica dos trabalhadores, que deveriam ser supridas por treinamentos e capacitações em serviço, são aprendidas na prática diária por intermédio dos atendimentos prestados, que percorrem fluxos inadequados e não resolutivos. Restam a esses trabalhadores conhecer a existência dos fluxos, mas admitem que:

(...) existe ainda muitas falhas, a maioria dos profissionais, inclusive os obstetras e as enfermeiras, logo no início elas não têm o conhecimento de como fazer, o que eu posso dizer, é o protocolo de andamento dessa paciente, algumas vezes. (T6, enfermagem, feminino).

Em virtude das modalidades de contratação da mão de obra dos trabalhadores, têm-se uma rotatividade de pessoal que acaba por interferir na sensibilização e envolvimento com a temática em questão, o que vem a fragilizar, sobremaneira, a longitudinalidade do processo de trabalho, como explicado nesta fala que:

Todos os dias a gente tem novos profissionais, então a fragilidade maior é a comunicação interna e sensibilização da equipe que a gente ainda não conseguiu, muita coisa para ser feita aí nesse sentido. (G4, medicina, feminino).

Os trabalhadores mostram-se também preocupados com a inexistência de articulação intersetorial e anunciam que a Rede de Atenção se encontra distante de se firmar, pois:

(...) a rede de apoio fora do hospital, eu acho que é uma fragilidade, a interdisciplinaridade, a rede de apoio, à falta de fluxo, falta de preparação dos profissionais, a falta de..., eu acho que é a preparação mesmo (...) (T4, enfermagem, feminino).

A ambiência imprópria também é citada como um fator complicador do processo de trabalho. As estruturas físicas inadequadas dificultam práticas humanizadas que contemplem e 
respeitem os momentos antagônicos pelos quais essas mulheres são expostas. $\mathrm{O}$ desabafo de $\mathrm{T} 7$ esboça o quão os serviços estão distantes de implementarem as diretrizes e as estratégias para prestarem uma assistência ética e legal:

Assim, são quartinhos separados, mas estão todos dentro de um cenário só. (...) Então essa indução do aborto acontece e do lado tem uma paciente em trabalho de parto, (...) eu acho até desumano, (...) tá convivendo em um ambiente de nascimento, (...) Então acho que tinha que ter um local para a curetagem, para o atendimento de mulheres em situação de aborto (...) e hoje a gente não tem isso. ( $\mathrm{T} 7$, medicina, feminino).

Outro ponto destacado por interferir negativamente na prática laboral se relaciona à perda de recursos financeiros. Esse quesito acaba por ancorar todos os pontos citados acima, pois, como referenda a verbalização:

A gente depende 100\% de recurso municipal e isso se o município está quebrado ou se o município está complicado em termos de repasse de recursos, atinge diretamente o serviço (...) desde a reforma predial, manutenção predial, a disposição e manutenção do maquinário de informática, de mobília, nós não temos acesso a isso. O que nós temos hoje já é do serviço desde a implantação em 2006 (...). Por exemplo, depois de 2012 não houve reformas (...). $O$ ambiente é acolhedor pelas profissionais que o fazem não pela estrutura física. (G1, serviço social, feminino).

\section{Limitações impostas pelas práticas de profissionais e gestores}

Para além das questões apontadas como fragilidades, existem aquelas que insurgem dos silenciamentos. T4, por exemplo, embora aponte a falta de articulação da rede, silencia sobre os protocolos e fluxos pactuados como eixos norteadores para o atendimento integral. Quando inquerida de forma direta sobre os fluxos, a informante expõe a ausência de capacitações ofertadas pelo serviço, além de se eximir de um compromisso firmado com o serviço para qual foi designado:

Não que tenha sido me repassado. (T4, enfermagem, feminino).

Alguns discursos surgem, desse modo, repletos de silêncios e contradições. O discurso de T10 verbaliza não existir um protocolo, embora reconheça que este está descrito na cartilha; justifica essa ausência por não ter sido criado um serviço; logo em seguida afirma que houve o treinamento dos profissionais para o serviço. $\mathrm{Na}$ sequência, T10 confirma a existência do protocolo, mas justifica a não utilização por motivos pessoais de alguns profissionais, silenciando sobre as estratégias existentes e preconizadas para minorar essa questão:

Era para seguir o que está na cartilha, como a gente não faz, não tem. É como eu já lhe falei, a gente não tem como, não segue um protocolo mesmo, porque não foi criado o serviço. O serviço foi treinado, mas não teve uma continuidade, mas tem o protocolo ele existe, do atendimento, o que é para fazer, mas nem todos os médicos querem atender, não tem seguimento, aí não adianta. (T10, enfermagem, feminino).

Neste contexto, vem à baila o discurso recorrente de que os dispositivos instrutivos e legais ficam restritos aos papéis e a inércia dos textos. Esta compreensão pode ser detectada na afirmação que margeia o senso comum, ao desabafar que:

No papel existe, na prática, na prática, eu não sei como é que faz não (...). (T10, enfermagem, feminino).

Cabe aqui ressaltar que a unidade onde T10 atua, no projeto inicial, existia um espaço destinado à assistência de mulheres em situação de violência sexual, mantendo sigilo e acolhimento. Nesse espaço havia, inclusive, área destinada à interrupção de gestações decorrentes de estupro. $\mathrm{O}$ prédio foi entregue com esses espaços reservados, mas decisões institucionais deslocaram a utilização desta área para outros fins.

Ao mesmo tempo em que a ausência de fluxos e protocolos é apontada como fragilidade, sua existência é sumariamente ignorada por alguns profissionais, como ilustra a fala de G5 ao afirmar:

Foi pensado o fluxo desse jeito, que era a gente atender, fazer o pré atendimento e encaminhar: a gente tinha um banner grande, mas ele se rasgou e ninguém fez outro. Já teve. (G5, medicina, feminino).

O silenciamento sobre o motivo de não ter sido refeito o banner com o fluxo de assistência descortina o desinteresse em favorecer o funcionamento efetivo da rede, fragilidade recorrente nas falas dos participantes.

Os discursos expõem ainda um modelo assistencial verticalizado e organizado em uma lógica de linha de produção, em que alguns profissionais se limitam aos aspectos técnicos, negligenciando a assistência integral preconizada:

O meu papel é só a parte médica, quando ela vem para mim, ela já passou pelo serviço de psicologia e da assistente social, tá tudo ok, então para mim fica só a parte médica de colocação do medicamento. (T8, medicina, masculino). 
Identifica-se que o distanciamento de muitos impede reconhecer a assistência às mulheres em situação de violência sexual como inerente ao seu trabalho, de modo que não existe apenas desconhecimento sobre o tema, mas um franco desinteresse quanto a questão. Nesse contexto, G2 afirma:

As principais fragilidades, eu acho, é o próprio conhecimento dos profissionais em geral, porque a gente informa e o povo faz que não sabe. Porque isso está com 2 a 3 anos que a gente montou aqui e ainda tem médico que diz que não sabia, embora a gente tenha divulgado na época através de WhatsApp, diretamente mostrando pro profissional e depois a pessoa diz que não sabia. Então assim eu acho que a grande fragilidade é essa, talvez o interesse dos profissionais em participar desse serviço, em fornecer para a paciente um serviço que é um direito dela. (G2, medicina, feminino).

O reconhecimento por parte do gestor de que o alegado desconhecimento é na verdade reflexo do desinteresse não motivou, contudo, ações de sensibilização. Embora silenciasse sobre a necessidade de sensibilização, G2 enfatizou a existência de aspectos documentais:

(...) eu fiz um resumo da apostila que a gente recebeu que era enorme, aí eu fiz um resumo para a pessoa não perder muito tempo lendo. Então tá tudo lá, realmente eu acho que falta um pouco de interesse dos profissionais em tomar conhecimento. (G2, medicina, feminino).

Evidencia-se que mesmo nas instituições que portam documentos protocolares e fluxos, estes não são acessados pelos trabalhadores, buscando outras formas de incentivar a leitura e aproximação com o tema:

A gente já colocou muito isso inclusive as revistinhas, tem um fluxo todinho, agora é como eu te falei as pessoas não levam isso muito a sério, não vou te dizer que isso é uma coisa que está bem arraigada porque não é. (G8, assistente social, feminino).

\section{Discussão}

Os resultados encontrados nesta pesquisa revelam que os lapsos nos processos de trabalho, podem vir a interferir de forma contundente na atenção às mulheres em situação de violência sexual. Os discursos verbalizam queixas sobre a inexistência de uma rede efetiva, progressivamente deteriorada nos últimos anos. O desmonte da atenção à saúde da mulher, principalmente no tocante aos direitos sexuais e reprodutivos ${ }^{19}$, passa pela via institucional ${ }^{20}$ e pelos baixos inves- timentos na área ${ }^{19}$. Esses lapsos assistenciais não são exclusivos do cuidado à saúde das mulheres. A redução do quantitativo de profissionais, a alta rotatividade e a falta de capacitação são fenômenos associados a fatores como a fragilidade dos vínculos empregatícios e o crescimento das terceirizações dos serviços de saúde, comprometendo a saúde do trabalhador ${ }^{21}$ e a qualidade da atenção ${ }^{22}$. Esta realidade, contudo, está associada ao desmonte das políticas públicas de saúde, e se faz presente em outras esferas ${ }^{23,24}$.

Outra fragilidade emergente nos discursos que não é uma exclusividade da assistência às mulheres em situação de violência sexual é a fragmentação e a verticalização da assistência. Embora existam esforços na direção de uma prática horizontalizada e integrada, são tímidos os movimentos de mudança desse modelo de atenção à saúde ${ }^{25}$, uma vez que, o paradigma biomédico prepondera nos serviços tradicionais de urgências e emergências, que "seguem funcionando de forma tradicional, na base da queixa-conduta, resultando em uma clínica reducionista e ineficaz [...]" Sendo assim, quando se trata da violência sexual, os atendimentos seguem esta mesma lógica sendo pautados nos sinais e sintomas evidentes com foco na medicalização e com pouca atenção voltada aos aspectos psicossociais ${ }^{26}$. Desta forma, os atendimentos ocorrem de forma direcionada à queixa principal, o que acaba por sucumbir a integralidade do cuidado ${ }^{8}$. Apesar das evidências que associam violência sexual ao desenvolvimento de transtornos mentais ${ }^{27}$, são recursivos os lapsos e barreiras de acesso que culminam na desassistência ${ }^{8,28}$. É importante salientar que nestes serviços perduram um histórico de precarização que se aprofunda e reflete retrocessos importantes nas políticas de saúde mental ${ }^{29}$.

As fragilidades da assistência à mulher em situação de violência sexual, contudo, possuem singularidades, na medida em que são reforçadas pelo contexto ideológico. O silêncio contingente do enunciatório ${ }^{15}$ marcou mais as ausências dos que as evidências dos principais lapsos inscritos nos processos de trabalho em questão.

Sobre a ambiência, a sua adequação é uma das estratégias planejadas para garantir a privacidade dessas mulheres que buscam por atendimento $^{30}$. É inconteste que a interrupção legal da gestação compartilhada em áreas destinadas a partos e nascimentos, compromete a humanização e contribui para revitimizar as mulheres. Esse fato associa-se em parte à decisão de incorporar os serviços de assistência à saúde da mulher em situação de violência sexual às maternidades pú- 
blicas, onde predominam inadequações da estrutura física ${ }^{31}$. Reconhecendo a gravidade dessas inconformidades, inexiste explicação coerente para o uso de recintos planejados, construídos e entregues com fins específicos de assistir mulheres em situação de violência sexual, deslocados para outros fins.

Os resultados reforçam a necessidade de capacitação continuada dos trabalhadores para a consolidação das políticas públicas ${ }^{32}$, visto que a não utilização de protocolos e fluxos assistenciais limitam a assistência prestada ${ }^{22}$. O não seguimento dos protocolos e fluxos reflete ainda lapsos da gestão, que não incorpora a violência sexual como uma demanda inerente ao serviço, culminando em acolhimentos sem responsabilização e encaminhamentos equivocados ${ }^{25}$. Os discursos evidenciam, contudo, que à ausência de capacitação soma-se o desinteresse de gestores e trabalhadores.

É importante ressaltar que "a integralidade constitui um elemento central para a consolidação de um modelo de saúde que incorpore, de forma mais efetiva, a universalidade e a equidade no atendimento às pessoas para alcançar ações resolutivas em saúde" ${ }^{\prime 3}$. Partindo da dimensão ética do cuidado, Franco e Merhy ${ }^{34,35}$ advogam que a habilidade de acolher as necessidades do outro não pode ser "aprendida" por nenhum saber específico, estando atrelada a processos relacionais e intersubjetivos. Nesse caso, há de se contextualizar esses discursos a fim de fazer emergir as formações ideológicas que pautam esse desinteresse - e, em alguns casos, obstrução - de parte dos trabalhadores em estruturar os serviços ou seguir os fluxos de assistência.

Para além das disciplinas de normalização oriundas do biopoder ${ }^{36}$, existem dispositivos sexopolíticos que colocam "o sexo" (a anatomia genital, as práticas sexuais, os códigos socioculturais de masculinidade e de feminilidade e as identidades) no cálculo do poder, fazendo desses discursos um agente de controle da vida ${ }^{37}$. Nesse contexto, não se pode ignorar que a subjetividade de muitos desses profissionais foram construídas em meio a esses processos discursivos ${ }^{38} \mathrm{e}$ a uma sexopolitica ${ }^{37}$ pautados pelo controle dos corpos e da sexualidade das mulheres ${ }^{36,39}$. Avanços de argumentos marcados pelo conservadorismo político e fundamentalismo religioso, como os que tem ganhado força no Brasil nos últimos anos ${ }^{19}$, não surgem de forma tão veemente sem que discursos socialmente normatizados os balizem ${ }^{15,38}$. Esses discursos, legitimados por organizações sociais, foram antes normatizados socialmente e cultu- ralmente sustentados por diversos processos discursivos e tecnologias de gênero ${ }^{38,39}$. Não à toa, a obstrução aos direitos sexuais e reprodutivos tem sido exposta e questionada em diversos países ${ }^{40,41}$, na medida em que não encontra justificativa no âmbito da Saúde Pública. Ao contrário, resulta no aumento da mortalidade feminina ${ }^{42}$, reforça uma estrutura social que subordina o papel social da mulher à sua capacidade reprodutiva ${ }^{43}$, além de predispô-la ao adoecimento psíquico ${ }^{44}$.

Destaque-se que a não identificação com as demandas das mulheres em situação de violência sexual não foi linear entre os profissionais. Os discursos de parcela das entrevistadas partiam de Formações Ideológicas diferentes, que reconheciam às necessidades de saúde das mulheres que assistiam e buscavam oferecer uma assistência integral ${ }^{45}$. Vale ressaltar que as diferenças ideológicas no que se refere ao atendimento e acolhimento das usuárias independem da categoria profissional, havendo maior afinidade nos discursos a depender do cenário de assistência do que da profissão em si. Essas profissionais, que participam efetivamente dessa assistência veem seu processo de trabalho obstruído em inúmeras frentes ${ }^{46,47}$, pois além da estigmatização ${ }^{46}$, os entraves no trabalho já causam sofrimento. Para $\mathrm{Clot}^{48}$, “(...) a eficácia profissional é fonte de saúde no trabalho quando a performance não é reduzida à abstração dos números".

Deste modo, a percepção do trabalhador em fazer um trabalho bem feito é um operador de saúde e a inexistência dessa experiência pôde ser vista como fonte de frustação e perda do sentido do trabalho para aqueles que se sentem sensibilizados para a importância desta questão. Com poucos profissionais sensibilizados, instala-se a sobrecarga de trabalho, que somada a forte pressão e a exiguidade dos tempos de pausa, repouso e recuperação podem impactar na saúde mental dos trabalhadores, que é indissociável da saúde como um todo ${ }^{49}$.

\section{Considerações Finais}

O estudo avança na discussão da temática da assistência à mulher em situação de violência sexual, na medida em que analisa os processos de trabalho envolvidos, partindo da Análise do Discurso, o que permite descortinar o que não está dito, mais está posto e naturalizado nas práticas cotidianas.

A fragmentação da atenção, o subfinanciamento dos serviços, a inadequação das estru- 
turas físicas, as lacunas na capacitação, o pouco quantitativo de profissionais e a alta rotatividade destes nos serviços agem em consonância com formações ideológicas pautadas no controle da sexualidade e dos corpos femininos, construindo um sistema complexo de fragilidades, que prejudica os processos de trabalho de assistência às mulheres em situação de violência sexual. Essas obstruções comprometem a atuação de profissionais e gestores sensibilizados, limitando a efetivação das políticas públicas específicas.

Diante desses achados, se faz premente a estruturação da rede de modo a efetivar e assegurar a posição de trabalhadores e gestores implicados nas equipes de atenção, viabilizar a sua qualificação continuada e promover ações de sensibilização para os demais. A inclusão da educação permanente voltada à abordagem da violência sexual na carga horária dos trabalhadores pode ser uma ferramenta para a participação e qualificação contínua do profissional. Acresce-se a isto, a incorporação efetiva da atenção à mulher em situação de violência sexual na rede de serviços por parte dos gestores na busca de assegurar a interdisciplinaridade, a intersetorialidade e a integralidade da atenção, além de garantir o respeito aos direitos sexuais e reprodutivos destas mulheres.

A efetivação destas medidas, demandam o reconhecimento das formações ideológicas que as obstruem. Vale destacar o contexto macropolítico brasileiro que, apesar da laicidade do Estado Brasileiro, temas como a garantia dos direitos sexuais e reprodutivos das mulheres, como a interferência na contracepção de emergência, discute-se fundamentada em dogmas religiosos e posturas moralistas de representantes do poder legislativo, cujas decisões retroagem nas conquistas das políticas públicas para as mulheres. Deste modo, é imperioso que os serviços se organizem para ofertarem proteção e atenção à mulher em situação de violência sexual se colocando na contracorrente da perda de direitos.

\section{Colaboradores}

JGO Branco, AVM Brilhante e LJES Vieira participaram da concepção, planejamento, análise, interpretação e redação do trabalho. MH Batista participou da revisão crítica do conteúdo. Todos os autores aprovaram a versão final. 


\section{Referências}

1. Souza MMS, Oliveira MVP, Jesus LA. Violência Sexual contra a mulher e o papel do enfermeiro, revisão de literatura. Cad Graduação-Cien Biol Saude 2016; 3(3):257-274.

2. Brasil. Ministério da Saúde (MS). Secretaria de Atenção à Saúde. Departamento de Ações Programáticas Estratégicas. Prevenção e tratamento dos agravos resultantes da violência sexual contra mulheres e adolescentes: norma técnica. Brasília: MS; 2012.

3. Signorelli MC, Hillel S, Oliveira DC, Ayala Quintanilla BP, Hegarty K, Taft A. Voices from low-income and middle-income countries: a systematic review protocol of primary healthcare interventions within public health systems addressing intimate partner violence against women. BMJ Open 2018; 8(3):e019266.

4. Oliveira CS, Delziovo CR, Lacerda JT. Redes de atenção à violência. Florianópolis: Universidade Federal de Santa Catarina; 2014.

5. Cecílio LCO, Merhy EE. A integralidade do cuidado como eixo da gestão hospitalar. In: Pinheiro R, Mattos RA. Construção da integralidade: cotidiano, saberes e práticas em saúde. Rio de Janeiro: IMS ABRASCO; 2003. p.197-210.

6. Menezes PRM, Lima IS, Correia CM, Souza SS, Erdmann AL, Gomes NP. Enfrentamento da violência contra a mulher: articulação intersetorial e atenção integral. Saude Soc 2014; 23(3):778-786.

7. Ruas APF. A precarização do trabalho em saúde mental e os possíveis impactos clínicos nos centros de atenção psicossocial de Campinas [dissertação]. Campinas: Universidade Estadual de Campinas; 2018.

8. Vieira EM, Hasse M. Percepções dos profissionais de uma rede intersetorial sobre o atendimento a mulheres em situação de violência. Interface (Botucatu) 2017; 21(60):52-62.

9. Lettiere A, Nakano AMS. Rede de atenção à mulher em situação de violência: os desafios da transversalidade do cuidado. Rev Eletr Enferm 2015; 17(4):1-8.

10. Cavalcanti LF, Moreira GAR, Vieira LJES, Silva RM. Implementação da atenção em saúde às violências sexuais contra as mulheres em duas capitais brasileiras. Saude Debate 2015; 39(107):1079-1091.

11. Instituto Brasileiro de Geografia e Estatística (IBGE). Brasil em sintese 2010 [página na Internet]. 2010 [acessado 2019 Jul 7]. Disponível em: https://cidades. ibge.gov.br/brasil/ce/fortaleza/panorama

12. Fórum Brasileiro de Segurança Pública. Anuário Brasileiro de Segurança Pública. Ano 12 [página na Internet]. 2018 [acessado 2019 Jul 7]. Disponível em: http://www.forumseguranca.org.br/wp-content/uploads/2019/02/Anuario-2019-v6-infogr\%C3\%A1fico-atualizado.pdf

13. Vinuto J. A amostragem em bola de neve na pesquisa qualitativa: um debate em aberto. Temáticas 2014; 22(44):203-220.

14. Creswell JW, Clark VLP. Pesquisa de Métodos Mistos. $2^{\mathrm{a}}$ ed. Porto Alegre: Penso Editora; 2013.

15. Orlandi EP. Discurso e Texto: formulação e circulação dos sentidos. Campinas: Editora Pontes; 2001.

16. Orlandi EP. Análise de Discurso: princípios e procedimentos. $8^{\mathrm{a}}$ ed. Campinas: Editora Pontes; 2009.
17. Pêcheux M, Fuchs C. A propósito da Análise $\mathrm{Au}$ tomática do Discurso: atualização e perspectivas. Tradução de Péricles Cunha. In: Gadet F, Hak T, organizadores. Por uma análise automática do discurso: uma introdução à obra de Michel Pêcheux. $3^{\text {a }}$ ed. Campinas: Unicamp; 1997 [1975]. p. 163-252.

18. Brasil. Resolução no 466, de 12 dezembro de 2012. Diretrizes e normas regulamentadoras de pesquisas envolvendo seres humanos. Diário Oficial da União; 2012.

19. Zanatta LF, Grein MI, Álvarez-Dardet C, Moraes SP, Brêtas JRS, Ruiz-Cantero MT, Roses M. Igualdade de gênero: por que o Brasil vive retrocessos? Cad Saude Publica 2016; 32(8):e00089616.

20. Oliveira ACD. Agendas de gênero nas políticas públicas no Brasil (1980-2016). Rev Feminismos 2018; $5(2 / 3): 1-6$

21. Druck G. A terceirização na saúde pública: formas diversas de precarização do trabalho. Trab Educ Saude 2016; 14(Supl. 1):15-43.

22. Vieira LJES, Silva ACF, Moreira GAR, Cavalcanti LF, Silva RM. Protocolos na atenção à saúde de mulheres em situação de violência sexual sob a ótica de profissionais de saúde. Cien Saude Colet 2016; 21(12):39573965.

23. Silva EB, Padoin SMM, Vianna LAC. Mulher em situação de violência: limites da assistência. Cien Saude Colet 2015; 20(1):249-258.

24. Santos WJ, Freitas MIF. Fragilidades e potencialidades da rede de atendimento às mulheres em situação de violência por parceiro íntimo. REME 2017; 21(e-):1-8.

25. Santos DS, Mishima SM, Merhy EE. Processo de trabalho na Estratégia de Saúde da Família: potencialidades da subjetividade do cuidado para reconfiguração do modelo de atenção. Cien Saude Colet 2018; 23(3):861-870

26. Barros LA, Albuquerque MCS, Gomes NP, Riscado JLS, Araújo BRO, Magalhães JRF. The (un) receptive experiences of female rape victims who seek healthcare services. Rev Esc Enferm USP 2015; 49(2):193200.

27. Medeiros MP, Zanello V. Relação entre a violência e a saúde mental das mulheres no Brasil: análise das políticas públicas. Estud Pesq Psicol 2018; 18(1):384403.

28. Minayo MCS, Souza ER, Silva MMA, Assis SG. Institucionalização do tema da violência no SUS: avanços e desafios. Cien Saude Colet 2018; 23(6):2007-2016.

29. Sousa FSP, Jorge MSB. O retorno da centralidade do hospital psiquiátrico: retrocessos recentes na política de saúde mental. Trab Educ Saude 2019; 17(1):e0017201.

30. Pinto LSS, Oliveira IMP, Pinto ESS, Leite CBC, Melo AN, Deus MCBR. Políticas públicas de proteção à mulher: avaliação do atendimento em saúde de vítimas de violência sexual. Cien Saude Colet 2017; 22(5):1501-1508.

31. Madeiro AP, Diniz D. Serviços de aborto legal no Brasil - um estudo nacional. Cien Saude Colet 2016; 21(2):563-572. 
32. Bezerra JF, Lara SRG, Nascimento JL, Barbieri M. Assistência à mulher frente à violência sexual e políticas públicas de saúde: revisão integrativa. Rev Bras Prom Saude 2018; 31(1):1-12.

33. Viegas SMF, Penna CMM. As dimensões da integralidade no cuidado em saúde no cotidiano da Estratégia Saúde da Família no Vale do Jequitinhonha, MG, Brasil. Interface (Botucatu) 2015; 19(55):1089-1100.

34. Franco TB, Merhy EE. Cartografias do trabalho e cuidado em saúde. Rev Tempus Actas Saude Colet 2012; 6(2):151-163.

35. Franco TB, Merhy EE. O reconhecimento de uma produção subjetiva do cuidado. In: Trabalho, produção do cuidado e subjetividade em saúde: textos reunidos. São Paulo: Hucitec; 2013. p. 151-171.

36. Foucault M. História da Sexualidade 1: a vontade de saber. São Paulo: Paz e Terra; 2015.

37. Preciado B. Multidões queer: notas para uma política dos “anormais". Rev Estud Feministas 2011; 19(1):1120.

38. Scott J. Gênero: uma categoria útil de análise histórica. Educ Realidade 1995; 20(2):71-99.

39. De Lauretis T. Technologies of Gender: Essays on Theo$r y$, Film, and Fiction. Bloomington: Indiana University Press; 1987.

40. Stahl RY, Emanuel EJ. Physicians, not conscripts-Conscientious objection in health Care. New Engl J Med 2017; 376(14):1380-1385.

41. Harries J, Cooper D, Strebel A, Colvin CJ. Conscientious objection and its impact on abortion service provision in South Africa: a qualitative study. Reprod Health 2014; 11:16.

42. Machado CL, Fernandes AMS, Osis MJD, Makuch MY. Gravidez após violência sexual: vivências de mulheres em busca da interrupção legal. Cad Saude Publica 2015; 31(2):345-353.

43. Despentes V. Teoria King Kong. São Paulo: n-1edições; 2016.
44. Fiala C, Arthur JH. There is no defence for 'Conscientious objection' in reproductive healthcare. Eur J Obstet Gynecol Reprod Biol 2017; 216:254-258.

45. Santos DS, Mishima SM, Merhy EE. Processo de trabalho na Estratégia de Saúde da Família: potencialidades da subjetividade do cuidado para reconfiguração do modelo de atenção. Cien Saude Colet 2018; 23(3):861-870.

46. Faúndes A, Duarte GA, Osis MJ. Conscientious objection or fear of social stigma and unawareness of ethical obligations. Int J Gynaecol Obstet 2013; 123:S57-S59.

47. Diniz D, Madeiro A, Rosas C. Conscientious objection, barriers and abortion in the case of rape: a study among physicians in Brazil. Reprod Health Matters 2014; 22(43):141-148.

48. Clot Y. O ofício como operador de saúde. Cad Psicol Social Trab 2013; 16(esp. 1):1-11.

49. Franco T, Druck G, Seligmann-Silva E. As novas relações de trabalho, o desgaste mental do trabalhador e os transtornos mentais no trabalho precarizado. Rev Bras Saude Ocup 2010; 35(122):229-248.

Artigo apresentado em 30/05/2019

Aprovado em 07/08/2019

Versão final apresentada em 02/12/2019 